\title{
PULMONARY OSSIFICATION WITH CARDIAC CALCIFICATION IN MITRAL VALVE DISEASE
}

BY

\author{
H. A. FLEMING* AND C. L. N. ROBINSON \\ From Sully Hospital, Glamorgan \\ Received February 24, 1957
}

Our purpose is to present eight cases of mitral valve disease with disseminated pulmonary ossification, in seven of which there was also massive calcification of the mitral valve or left atrium or both. Of these five were seen by us at this hospital and are the only cases of pulmonary ossification in association with mitral valve disease that have been seen here up to the present: the other three were studied from their records.

Pulmonary ossification is rare and cardiac calcification not common, and the combination of the two must be unusual. Wagner in 1859 first reported bone formation in the lungs in a woman aged 25 years with dropsy. Salinger (1932) first recognized the relation of bony nodules to mitral valve disease and reported a second case. Other reports have been made by Wells and Dunlap in 1943 (1 case) and by Grishman and Kane in 1945 (8 cases). Elkeles and Glynn (1946) described the first case in England. In 1947 Elkeles reported a further case in which the appearances are very different from all other cases: it would appear from the radiograph to be almost certainly a case of calcified pulmonary tuberculosis. Later reports have been made by Lawson (1949), Lendrum et al. (1950, 3 cases), Sahn and Levine (1950), Kerley, (1951), Schinz et al. (1953), Steiner and Goodwin (1954, 2 cases), and Short (1955) (1 case each unless stated). In many of these reports the condition is referred to in passing, and the clinical and pathological details are often very few. Whitaker et al. (1955) presenting 7 new cases in detail, give an excellent review and a discussion of the ætiology.

Calcification of the mitral valve is common in mitral valve disease and is recorded in all recent series. For example Wood (1954) reported some degree of calcification in 28 per cent of cases submitted to mitral valvotomy and heavy calcification in 50 per cent of those with a significant degree of mitral incompetence.

Calcification of the left atrium was first described radiologically by Shanks et al. (1938). Ruskin and Samuel (1952) reviewed the only 18 cases they found described in life and added 2 new ones: they view it as a rare condition usually associated with mitral valve disease. The calcification is subendocardial and varies from isolated plaques in the posterior wall to involvement of the entire atrial wall, and in some cases the mitral valve was also calcified. Steiner and Goodwin (1954) mention 2 in a series of 91 cases. The relevant features of our cases are summarized in Table 1.

All the patients except Case 4 were submitted to operation for mitral valvotomy. (Cases 1, 2, and 3 by Mr. Dillwyn Thomas, Case 5 by Mr. H. R. S. Harley, Case 7 by Mr. O. S. Tubbs, and Cases 6 and 8 by Mr. Ian Hill.) In all the operated cases the areas of ossification could be easily felt in the lung substance.

Case 1 (Fig. 3) is of interest in that the entire wall of the left atrium was calcified and this process extended along all the pulmonary veins so that no access to the mitral valve was possible by the accepted methods of the time. The calcium appeared to be within the wall rather than in thrombus.

\footnotetext{
* Present address: Brompton Hospital, London, S.W.3.
} 

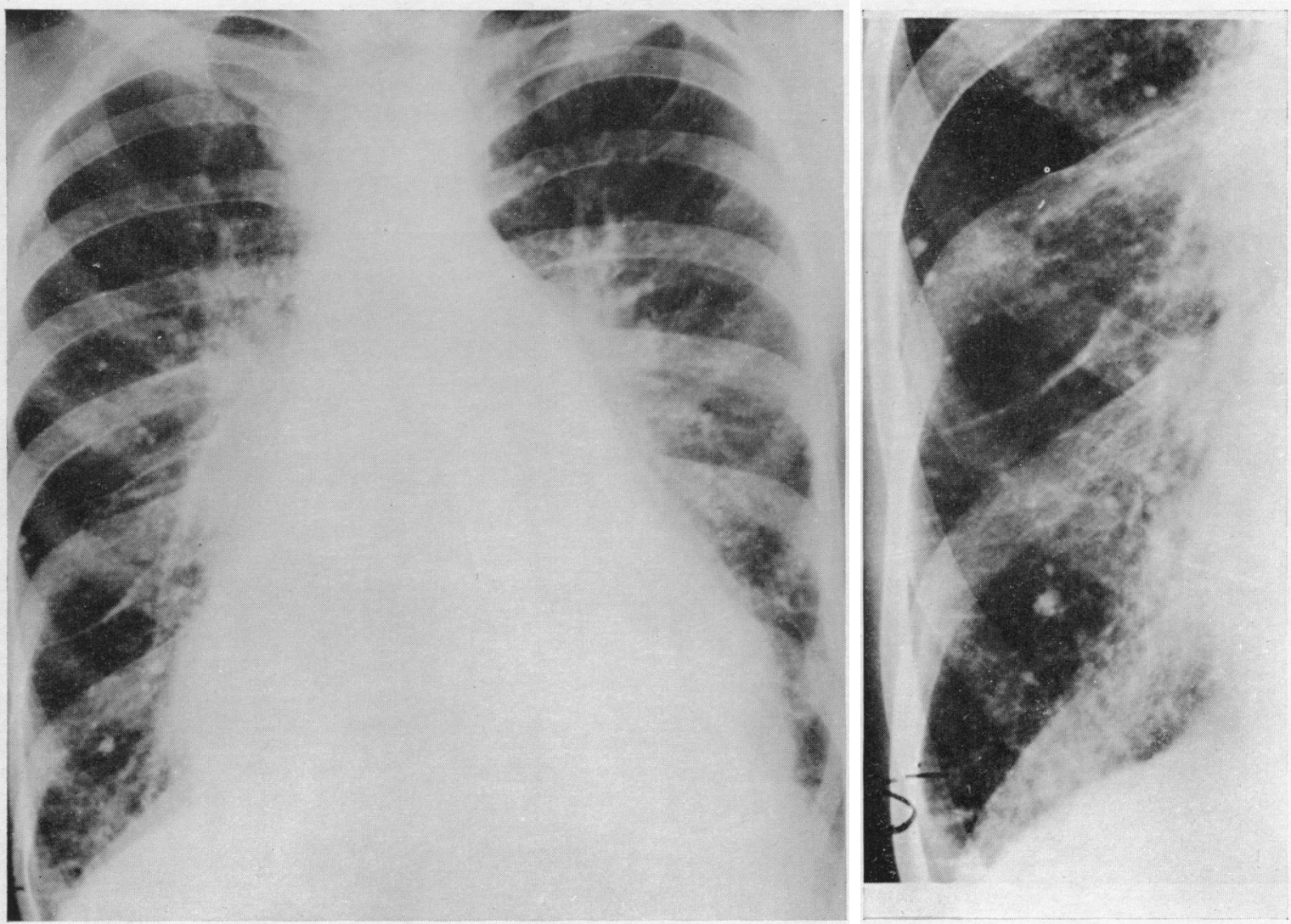

Fig. 1.-Case 1. P.A. chest radiograph, showing the features of pulmonary FIG. 2.-Case 1. Detail of the radiohypertension and the interlobular septa that were seen in all cases. The pulmonary ossification is most obvious in the right lower zone. graph of the right lower zone, showing the interlobular speta and the inconspicuous pulmonary arteries.

TABLE I

Details of CASEs. No patient had suffered any symptoms of left-sided heart failure, all of them showed marked interlobar septal lines and all had evidence of a raised pulmonary vascular resistance. None of them had radiological hæmosiderosis.

\begin{tabular}{|c|c|c|c|c|c|c|c|c|c|c|c|}
\hline $\begin{array}{l}\text { Case } \\
\text { No. }\end{array}$ & $\begin{array}{l}\text { Sex and } \\
\text { age }\end{array}$ & $\begin{array}{l}\text { Age of } \\
\text { chorea or } \\
\text { rheu- } \\
\text { matic } \\
\text { fever }\end{array}$ & $\underset{\text { P.A.P. }}{\text { mm. }}$ & $\begin{array}{c}\text { Hæmo- } \\
\text { ptysis }\end{array}$ & $\begin{array}{c}\text { Mitral } \\
\text { syst. } \\
\text { murmur }\end{array}$ & $\begin{array}{c}\text { Conges- } \\
\text { tive } \\
\text { heart } \\
\text { failure }\end{array}$ & $\begin{array}{l}\text { Calcium } \\
\text { in heart }\end{array}$ & $\begin{array}{l}\text { Bone in } \\
\text { lungs }\end{array}$ & $\begin{array}{c}\text { Maximum } \\
\text { diameter } \\
\text { of } \\
\text { lung } \\
\text { bone }\end{array}$ & $\underset{\text { biopsy }}{\text { Lung }}$ & $\begin{array}{l}\text { Hæmo- } \\
\text { siderin } \\
\text { present at } \\
\text { biopsy }\end{array}$ \\
\hline 1 & M. 24 & $8,12,16$ & $80 / 60$ & & \pm & + & & $\begin{array}{l}\text { All zones, } \\
\text { espec. R.L.Z. }\end{array}$ & & Bone & \pm \\
\hline $\begin{array}{l}2 \\
3 \\
4\end{array}$ & $\begin{array}{l}\text { M. } 30 \\
\text { M. } 40 \\
\text { M. } 49\end{array}$ & $\begin{array}{l}-\overline{8,20} \\
10,11\end{array}$ & $\begin{array}{r}90 / 30 \\
125 / 50 \\
-\end{array}$ & for $\overline{14}$ yr. & $\bar{z}$ & $\frac{+}{-}$ & $\begin{array}{l}\text { M.V. } \\
\text { L.A. } \\
\text { L.A. \& }\end{array}$ & $\begin{array}{ll}\text {," } & \text {," } \\
\text {," } & \text {," }\end{array}$ & $\begin{array}{l}5 \mathrm{~mm} \text {. } \\
7 \mathrm{~mm} \text {. } \\
5 \mathrm{~mm} \text {. }\end{array}$ & $\begin{array}{l}\text { Bone } \\
\text { Bone } \\
\text { N.D. }\end{array}$ & $\overline{\bar{N}} \overline{\mathrm{D}}$. \\
\hline 5 & M. 34 & - & $100 / 50$ & small, & \pm & - & M.V. & & $4 \mathrm{~mm}$. & Bone & - \\
\hline 6 & M. 35 & - & 52 & 9 and 7, & \pm & + & M.V. & & $3 \mathrm{~mm}$. & Bone & \pm \\
\hline 7 & M. 33 & 16 & 50 & $\begin{array}{l}\text { yr. ago } \\
\text { slight } 4\end{array}$ & - & - & M.V. & All zones & $4 \mathrm{~mm}$. & N.D. & N.D. \\
\hline 8 & F. 34 & 10 & 50 & mo. ago & - & - & Nil. & $\begin{array}{l}\text { Both lower \& } \\
\text { mid. zones, } \\
\text { espec. R.L.Z. }\end{array}$ & $3 \mathrm{~mm}$. & N.D. & N.D. \\
\hline
\end{tabular}

L.A. Left atrium. $\quad$ M.V. Mitral valve.

N.D. Not done.

R.L.Z. Right lower zone. P.A.P. Pulmonary artery pressure (in mm. Hg). In Cases $1,2,3$, and 5 the pressures are as recorded at L.U.Z. Left upper zone.
P.A.P. Pulmonary artery pressure (in mm. Hg). In Cases $1,2,3$, and 5 the pressures a
catheterization and in Cases 6,7 , and 8 they are means recorded at thoracotomy. 
Case 3 had worked as a miner from the age of 14 to 18 years when he was told that he must no longer work: this he had obeyed for 22 years and by the time we saw him he was greatly disabled. In spite of the apparently unpromising situation (Table I and Fig. 4 and 5), within two months of valvotomy he had evidence of a much lower pulmonary vascular resistance and was working for the first time for 22 years.

Three cases had been in right-sided heart failure and had been treated for this. The other

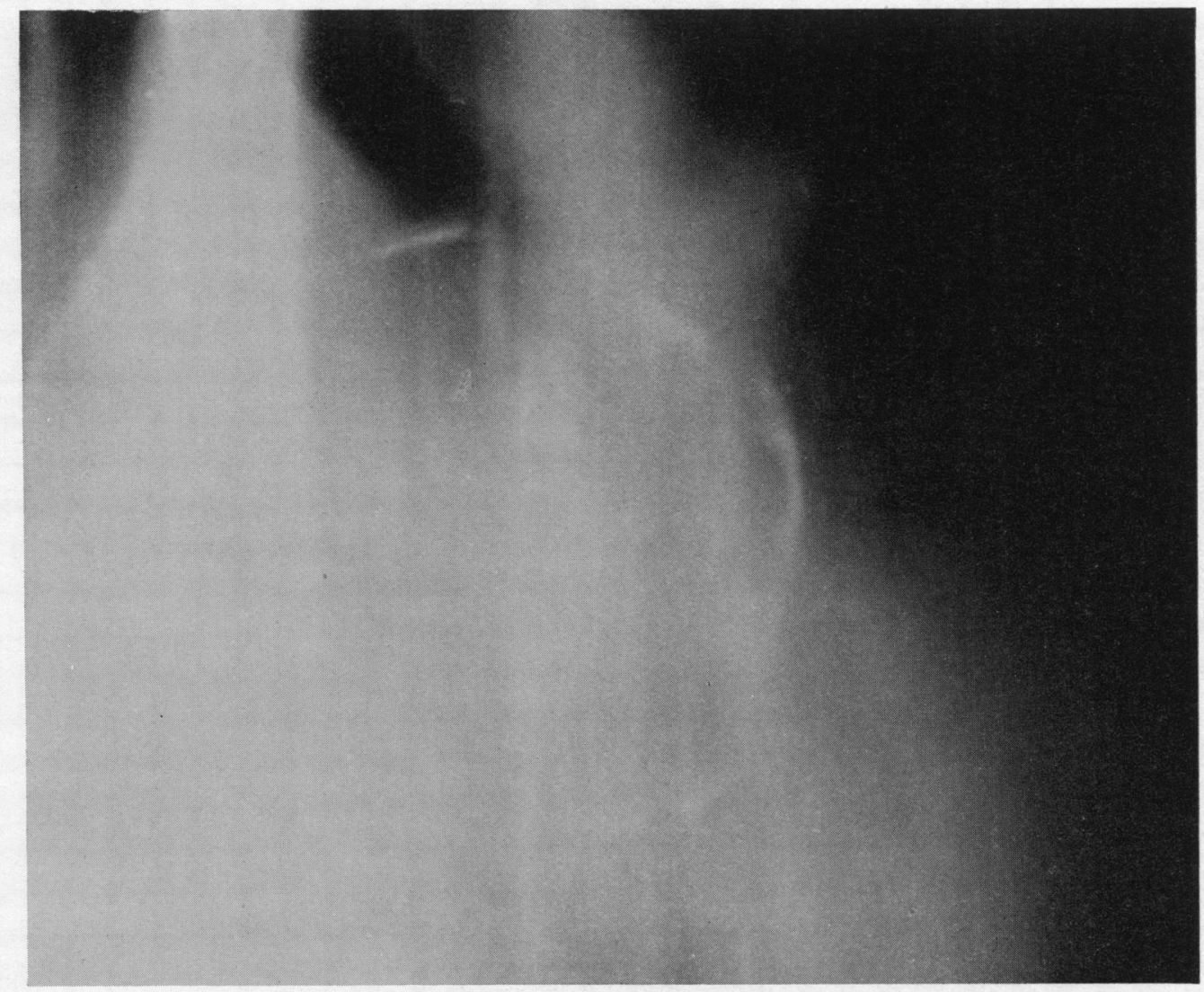

FIG. 3.-Case 1. Tomograph in the right anterior oblique position, showing sheet of calcium in the left atrial wall.

five had not been so treated over a long period and it is unlikely that the treatmen: made any positive contribution to the appearance of the calcification.

The absence of clinical left-sided heart failure was judged by the complete lack of cardiac asthma, paroxysmal nocturnal dyspnœa, and orthopnœa in each case.

Interlobular septal lines (Kerley's B lines) were clearly visible in all cases on the P.A. radiograph. No attempt has been made to assess these quantitatively as great differences in appearance can be produced by variations in radiological technique. They were always much more prominent than in average cases of mitral stenosis.

Pulmonary vascular resistance was judged on clinical, radiological, and cardiographic grounds as described by Wood (1954) or on the pressures recorded at catheterization or operation (Table I). In Cases 1, 2, and 5 histology of the pulmonary arterioles in the biopsy also showed changes of pulmonary hypertension. In Cases 3 and 6 no suitable vessels were seen in the material. In all cases the evidence in favour of a high resistance was strong. The cardiographic changes of 
right ventricular hypertrophy were extreme: the radiographs when shown to an experienced observer were all reported as high resistance mitral disease, and the surgeons found much right ventricular hypertrophy and dilatation of the pulmonary artery. Indirect left atrial pressure could only be obtained in Case 2 (mean $18 \mathrm{~mm}$. $\mathrm{Hg}$ ) so resistances were not calculated, but they were obviously extreme, with high pulmonary arterial pressures and low cardiac outputs.

Hæmoptysis was not a conspicuous feature except in Case 3 who had had frequent hæmoptyses for 14 years. The areas of ossification were particularly striking in this case (Fig. 4 and 5). Cases 5 and 6 had small hæmoptyses some years previously, and Case 7 four months previously, but the other four had never coughed blood.

No case had evidence of disease in valves other than the mitral. In four there was a mild mitral systolic murmur but in none was this judged to represent significant mitral incompetence. This conclusion was fully supported by the surgical findings.

All cases except the woman had gross calcification in the heart. This was seen on fluoroscopy and was studied and confirmed by tomography and at operation. In four it was in the mitral valve, in two in the left atrium, and in one in both. It was always easily seen. Case 1 (Fig. 3), showed the left atrial calcification most strikingly; in Case 3 it was in the superior portion of the wall and in Case 4 it encircled the superior and posterior walls.

The pulmonary ossification was usually evident in all zones of the lungs but was always most dense in the lower zones especially on the right, and least prominent in the upper zones particularly the left. The shadows were irregular in outline and size and varied from barely visible to up to $3 \mathrm{~mm}$. in diameter in all cases. In most they were also larger than this (Table I) and in Case 3 were up to $7 \mathrm{~mm}$. in diameter (Fig. 5).

Hæmosiderosis was not seen radiologically in any case, nor was it diagnosed in the biopsy in the five examined. In two of them small amounts of hæmosiderin were present in the lung around the bone, in macrophages usually. The nodules were found to be of bone in each of the five where biopsy was made. All the patients are still living and there is no evidence of the state of the calcium in the heart, but it did not appear to differ from the calcium found in other cases of rheumatic valvular disease.

\section{DifFerential Diagnosis}

The presence of small, irregular, calcified lesions, diffusely spread throughout the lower and middle zones of both lungs in a male patient with clinical and radiological signs of mitral valve disease and pulmonary hypertension should obviate a diagnosis of any other cause for the calcification.

Among such other types is a coarse branched form of ossification of unknown ætiology, affecting predominantly elderly men in the lower zones of both lungs (Schinz et al., 1953); it occurs in interstitial tissue. Again, Microlithiasis alveolaris pulmonum (Puhr, 1933) is a sequel to chronic inflammation, causes a large number of fine nodules in both lungs with least involvement of the apices, and may be so extensive as to cause death from respiratory failure. The texture of the lung at autopsy is like that of pumice stone and the sawn surface feels like sandpaper. The tiny concretions occur in alveoli and may be washed out like grains of sand.

The calcification of miliary tuberculosis is finer and more diffuse and affects all lung zones. The distribution and character of calcification in other forms of pulmonary tuberculosis is distinctive. Infection with Histoplasma capsulatum may cause fine diffuse calcification in both lungs, but this and infection with Coccidiodes immitis occur endemically, and each may be confirmed by specific laboratory investigations. Other opacities that need differentiation include those of sarcoidosis, leukæmia, Hodgkin's disease, pneumoconiosis, hæmosiderosis, and lymphangitis carcinomatosa.

\section{PATHOLOGY}

The pathological features of the bone in our five cases that were biopsied are similar to those already reported by Elkeles and Glynn (1946) and Whitaker et al. (1955). The bone is of the 
woven type, is intra-alveolar, and may contain bone marrow. Because of the identical X-ray and operation findings in our other three that had no biopsy, it seems reasonable to suppose that the changes were the same. The nodules in our Case 3 (Fig. 5) are unusually numerous and measured up to $7 \mathrm{~mm}$. in diameter. Hæmosiderin was an inconspicuous feature of the biopsies and we have

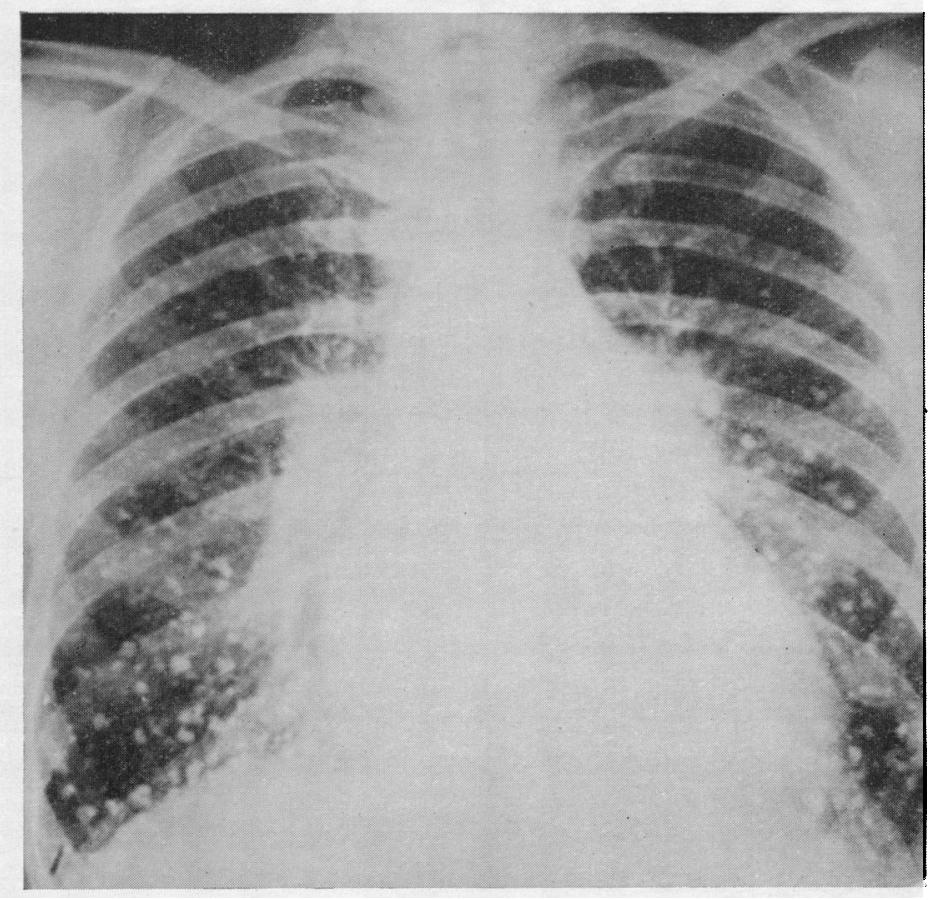

Fig. 4.- Case 3. P.A. chest radiograph, showing features of pulmonary cation of wide distribution. The left upper zone is least involved and the right lower zone most involved.

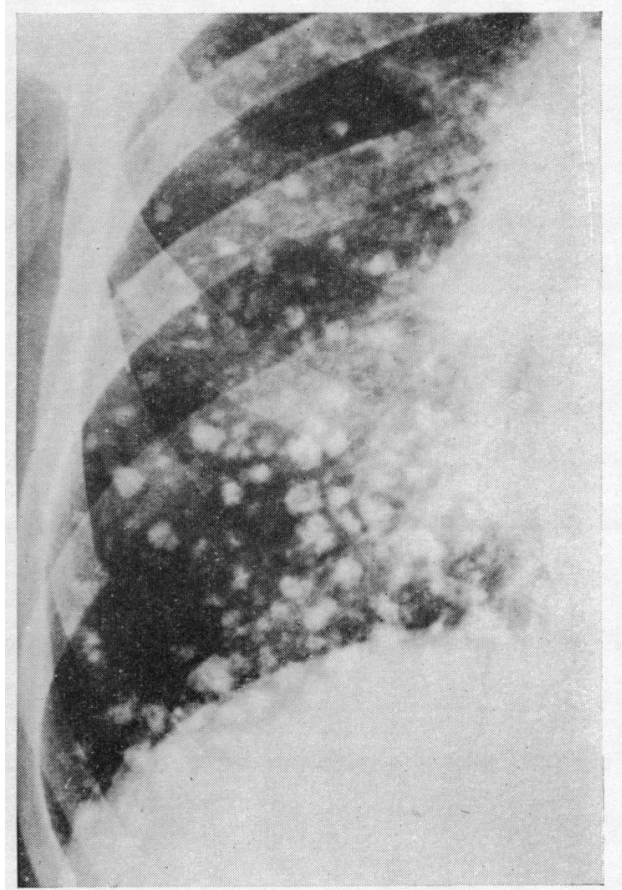

FIG. 5.-Case 3. Detail of the radiograph of the right lower zone, showing the largest and the most numerous areas of ossification. In this penetrated film the lines of the interlobular septa which were present are not apparent.

therefore no evidence to support Lawson (1949) and Ellman and Gee (1951) who suggest that there may be a relationship between hæmosiderosis and pulmonary ossification. The concentration and size of the nodules tended to be greatest in the lower lobes, especially on the right, but was sometimes almost universal as in Case 3 (Fig. 4). The upper lobes were least involved, particularly the left.

\section{Clinical and Radiological Features}

The ages of our patients ranged from 24 to 49 years. The incidence of rheumatic fever ( 5 of 8 cases) was similar to that reported in cases of pure mitral stenosis (Wood, 1954).

It is interesting that 7 of our 8 cases were men. The woman (Case 8) had pulmonary ossification and the other clinical features, but she was lacking in intracardiac calcification. Whitaker et al. (1955) had only one woman among their 7 cases, and a high incidence of men is found throughout the reports of pulmonary ossification in mitral valve disease. Considering the relatively greater frequency of mitral stenosis in women, this probably represents a much higher incidence of the condition in men.

We have no studies of calcium or hormone metabolism in our patients, but note that Allbright (1947) produces evidence of the influence of sex hormones on bone formation. Sparks et al. (1955) and Lostroh and Choh $\mathrm{Hao} \mathrm{Li}(1955)$ have made interesting observations on the effects in 
the mouse of cortisone on the deposition of calcium in various viscera, including the heart. Though they have not found these deposits in the lung (Lostroh, 1956) it is possible that their work may prove to have some bearing on the subject. Further than to suggest that pulmonary ossification and massive deposits of calcium in the heart may be the result of steroid stimulation, we have nothing further to offer and discussion will be limited to the pulmonary ossification. The first case of Whitaker et al. (1955) a man, aged 30, with calcific mitral and aortic stenosis would fit into our group. The high incidence of gross calcification of the mitral valve is noteworthy in our group. In surgical cases Wood (1954) found moderate or heavy calcification in only 12 per cent and most of these had significant incompetence, a feature entirely lacking in our cases where gross mitral calcification was present in 5 of the 8 cases.

Hamoptysis. Hæmoptysis in mitral stenosis may be of five different kinds (Wood, 1954) and it is likely that our cases could, at times, have been liable to most of these. In retrospect it is impossible to classify this symptom and to compare it with the reported incidences. Hæmoptysis was a striking feature in one only, though it had occurred in minor degree in three others. It is recognized that hæmosiderosis can be found without overt hæmoptysis, but there was no radiological or biopsy evidence of hæmosiderosis in this group. Hæmoptysis has not been a feature of most previous reports of pulmonary ossification.

Pulmonary Venous Congestion. None of our cases had at any time suffered symptoms of pulmonary venous congestion but all showed well marked transverse interlobular lines in the lower lobe of each lung. These we interpret as meaning that at some time these patients had suffered from a raised left atrial pressure with pulmonary venous congestion. These lines were first radiologically described by Kerley (1933) and have caused increasing interest in recent years when they have been the subject of numerous reports, e.g. Fleischner and Reiner (1954) and Short (1955). While some workers (Whitaker and Lodge, 1953; Goodwin et al., 1955) have sought to relate their occurrence to the presence of pulmonary arterial hypertension, there is now good evidence (Carmichael et al., 1954; Bruwer et al., 1955; Gough, 1956; and Rossall and Gunning, 1956) to suggest strongly that the important factor in mitral valve disease is the rise of pulmonary venous pressure. We agree with Grainger and Hearn (1955) that conditions such as mediastinal reticulosis or neoplasms, sarcoidosis, and pneumoconiosis can produce these lines and, in addition, we have observed them following hæmoptysis and during the use of lateral recumbency for tuberculous cavity closure. In mitral valve disease the transient lines would appear to be due to œdema of the interlobular septa while the more permanent type may be due to hæmosiderin deposition or to chronic fibrous thickening of the septa. In each case there is good evidence that, at the time of their production at least, there is a raised pulmonary venous pressure. Such lines are not easy to reproduce in figures particularly as the penetration most suitable for their demonstration is not best suited to showing pulmonary ossification. However, careful perusal of the radiographs reproduced in various papers on pulmonary ossification already mentioned shows these lines to be present commonly. This is certainly so in Cases 5 and 7 and probably in Case 3 of Whitaker et al. (1955).

Pulmonary Vascular Resistance. Clinical evidence of raised pulmonary vascular resistance was present in all our cases, and the level of the pulmonary artery pressure was measured at catheterization in four and at operation in another three (Table I). In the seven cases of Whitaker et al. (1955) there was clinical evidence of pulmonary hypertension in six, and in the seventh there was cardiographic evidence of right ventricular hypertrophy. In all other cases of pulmonary ossification where there are sufficient details published there is good evidence of severe pulmonary hypertension. This is true even in the early reports of Elkeles and Glynn (1946) where the radiograph suggests pulmonary hypertension and, as Heath and Whitaker (1955) have already suggested, the histological changes they interpreted as rheumatic arteritis were probably those of fibrinoid necrosis associated with pulmonary hypertension.

While we would agree with the concept of Wood (1954) that most patients with a very high pulmonary vascular resistance have never had any symptoms of pulmonary venous congestion and developed their extreme resistance at a relatively early stage in the course of the disease, we do feel 
that the present small group of cases forms an exception. There is evidence in the transverse lines that there had been pulmonary venous congestion and yet when seen they had severe pulmonary hypertension. Whitaker et al. (1955) have also made this suggestion but without amplification or mention of the horizontal lines. We would therefore agree with the suggestion of Lendrum et al. (1950) that the ossification develops in areas of pulmonary œdema, the œdema in our cases being sub-clinical. Whether the development of pulmonary hypertension with narrowing of the arterioles and diminution of blood flow has any direct bearing on this is difficult to say. In other areas of the body local ischæmia promotes calcification, but with the double blood supply to the lungs the explanation is unlikely to be so simple. It is of interest that the ossification in the lungs is always greatest in the lower zones where the narrowing of the pulmonary arteries is most pronounced. This similar distribution suggests that the two findings may be related. It is possible that the secondary development of a raised pulmonary vascular resistance in these cases merely permits a sufficiently long survival after asymptomatic pulmonary œdema to allow ossification to occur.

\section{SUMMARY}

Eight new cases of pulmonary ossification in mitral stenosis are reported: seven were men who had also massive calcification in the mitral valve or the left atrium. The possible influence of steroids is discussed.

These 8 cases and many of those previously reported had severe pulmonary hypertension and well-marked interlobular septal lines in the lower zones. It is suggested that pulmonary ossification develops in a small group of patients, the natural history of whose disease includes both subclinical pulmonary œdema and elevation of the pulmonary vascular resistance.

We would like to thank Mr. Dillwyn, Mr. E. Thomas, Mr. H. R.S. Harley, Dr. L. R. West, and Dr. H. M. Foreman of Sully Hospital, under whose care Cases 1, 2, 3, and 5 were investigated and treated. Dr. P. E. Dipple kindly allowed us to see Case 4 . Dr. G. Simon drew our attention to Cases 6, 7, and 8, and Dr. C. Baker, Dr. G. Hayward, Mr. O. S. Tubbs, and Mr. Ian Hill were kind enough to give us access to their records of these cases. We are grateful to Mrs. B. Marshall for the photographs and Miss P. Edwards for secretarial assistance.

\section{REFERENCES}

Allbright, F. (1947). Recent Progress in Hormone Research, 1, 293.

Bruwer, A. J., Ellis, F. H., and Kirklan, J. W. (1955). Circulation, 12, 807.

Carmichael, J. H. E., Julian, D. G., Penrhyn-Jones, G., and Wren, E. N. (1954). Brit. J. Radiol., $27,396$.

Elkeles, A. (1947). Proc. Royal Soc. Med., 40, 405.

, and Glynn, L. E. (1946). J. Path. Bact., 58, 517.

Ellman, P., and Gee, A. (1951). Brit. med. J., 2, 384.

Fleischner, F. G., and Reiner, L. (1954). New Eng. J. Med., 250, 900.

Goodwin, J. F., Hunter, J. D., Cleland, W. P., Davies, L. G., and Steiner, R. E. (1955). Brit. med. J., $2,573$.

Gough, J. (1956). Lancet, 1, 749.

Grainger, R. G., and Hearn, J. B. (1955). J. Fac. Radiol. Lond., 7, 66.

Grishman, A., and Kane, I. J. (1945). Amer. J. Roent., 53, 575.

Heath, D., and Whitaker, W. (1955). J. Path. Bact., 70, 291.

Kerley, P. (1933). Brit. med. J., 2, 594.

Lawson, H. M. (1949). Brit. med. J., 1, 433.

Lendrum, A. C., Scott, L. D. W., and Park, S. D. S. (1950). Quart. J. Med., 19, 249.

Lostroh, A. (1956). Personal communication.

, and Choh Hao Li (1955). Nature, 176, 504.

Puhr, L. (1933). Virch. Arch., 290, 156.

Rossall, R. E., and Gunning, A. J. (1956). Lancet, 1, 604.

Ruskin, H., and Samuel, E. (1952). Amer. Heart J., 44, 333.

Sahn, S. H., and Levine, I. (1950). Arch. intern. Med., 85, 483.

Salinger, H. (1932). Fortshr. Röntgenstr., 46, 269.

Schinz, H. R., Baensch, W. E., Friedl, E., and Uehlinger, E. (1953). Roentgen Diagnostics, Vol. 3. Wm. Heinemann, London.

Shanks, S. C., Kerley, P., and Twining, E. W. (1938). Text book X-ray Diagnosis, Vol. 1. H. K. Lewis, London.

Short, D. S. (1955). Brit. Heart J., 17, 33.

Sparks, L. L., Rosenau, W., MacAlpine, R.N., Daane, P. A., and Choh Hao Li (1955). Nature, $176,503$.

Steiner, R. E., and Goodwin, J. F. (1954). J. Fac. Radiol. Lond., 5, 167.

Wells, H. G., and Dunlap, C. E. (1943). Arch. Path., 35, 420.

Whitaker, W., and Lodge., T. (1953). J. Fac. Radiol. Lond., 5, 182.

, Black, A., and Warrack, A. J. M. (1955.). J. Fac. Radiol. Lond., 7, 29.

Wood, P. (1954). Brit. med. J., 1, 1051. 